\title{
A socio-biological explanation for social disparities in non-communicable chronic diseases: the product of history?
}

\author{
C M Schooling, G M Leung
}

Department of Community Medicine, School of Public Health, Li Ka Shing Faculty of Medicine, The University of Hong Kong, Hong Kong SAR, China

\section{Correspondence to} Dr C M Schooling, School of Public Health, The University of Hong Kong, Units 624-627, Core F, Cyberport 3, Pokfulam, Hong Kong SAR, China;

cms1@hkucc.hku.hk

Accepted 16 December 2009 Published Online First 1 June 2010

\begin{abstract}
This study places social disparities in the major non-communicable chronic diseases within their global economic and historical contexts. Rapid economic transition outside the developed world provides a unique opportunity to re-examine the origins of, and biological mechanisms driving, social disparities. Gaps in prevailing theories focusing on material resources, civic infrastructure and social structure are identified. Using longstanding experimental evidence and epigenetic theories, it is suggested that exposure to economic development over generations (ie, improved living conditions over historical time) could by acting on different biological axes (somatotrophic and gonadotrophic) generate specific patterns of social disparities. Moreover, these same processes could initially generate a transient epidemic of diabetes as well as a permanent increase in male risk of premature ischaemic heart disease. As such, this study demonstrates the importance of context, and implies that current evidence from the developed world may be largely uninformative for preventing or mitigating social disparities in non-communicable chronic diseases elsewhere, suggesting research efforts should be focused on developing countries.
\end{abstract}

\section{INTRODUCTION}

Social disparities in health are pervasive and persistent. Impoverished environments indisputably lead to ill health, emphasising the importance of environmental conditions, encompassing material resources, civic infrastructure and social structure. Key to mitigating the effects of social disparities on health, indeed of any environmental threats, is to understand completely the aetiologic pathways through which adverse consequences are generated. Although the literature is populated with explanations for the multiple pathways by which the embodiment of lack of resources, social exclusion and discrimination may damage health, ${ }^{1}$ there are important gaps.

Social disparities have been most extensively documented in developed countries, albeit from different perspectives. In the USA, emphasis was initially on racial disparities in health, ${ }^{2}$ perhaps because of the civil rights movement and ideal of a classless society. In contrast, in the UK, greater emphasis has been placed on socio-economic disparities in health, at least since the 1980 Black Report ${ }^{3}$ in the present era. Despite political opposition, the underlying explanation is recognised as deprivation, ${ }^{4}$ although which of the multiple dimensions of deprivation are most important in generating disparities is difficult to distinguish from inevitably observational studies. Nevertheless, lack of personal resources and public infrastructure ${ }^{5}$ throughout life are recognised as important factors, ${ }^{4}$ with a heated debate as to whether a neomaterial explanation is sufficient or whether depletion of social capital, stresses of low status or prestige, lack of power or invidious comparisons also make a difference. ${ }^{5-9}$ This debate is difficult to resolve because the processes and pathways by which social disparities generate diseases are not fully elucidated. However, it is increasingly important for non-communicable chronic diseases in the developing world. With economic development, rising national incomes and the associated changes in life expectancy, nutrition and lifestyle, chronic diseases are expected to be responsible for an increasing share of global deaths in developing countries over the next 20 years. ${ }^{10}$

Most current theories concerning disparities in chronic disease originate from observations in longterm developed Caucasian populations. Evolution of disparities over time in parallel with economic development, either considered as historical time or as epidemiological time relative to the start of economic development, is not usually considered. This missing dimension may result in empirically driven hypotheses, which are inappropriate for, or easily disproved in, populations with different histories of economic development. Current rapid economic development and industrialisation in the developing world provides a unique opportunity to re-examine the origins and biological mechanisms driving social disparities. Below, social disparities in the major non-communicable diseases (ie, cardiovascular diseases (ischaemic heart disease (IHD) and stroke) and diabetes) are placed within their global and historical contexts, which may provide clues as to how the emergence of these disparities can be prevented and/or mitigated most effectively in transitioning economies.

\section{GLOBAL CONTEXT \\ Disparities between countries}

Figure 1 shows the current association between national income (gross domestic product (GDP) per head ${ }^{11}$ ) and mortality (age-standardised mortality per 100000 ) from stroke and IHD, where available (153 countries). ${ }^{12}$ Figure 2 shows the current association between national income and morbidity from diabetes (age-standardised disability adjusted life years per $100000^{12}$ ) for these same countries. ${ }^{13}$ In all cases, assessed from model fit (data not shown), 


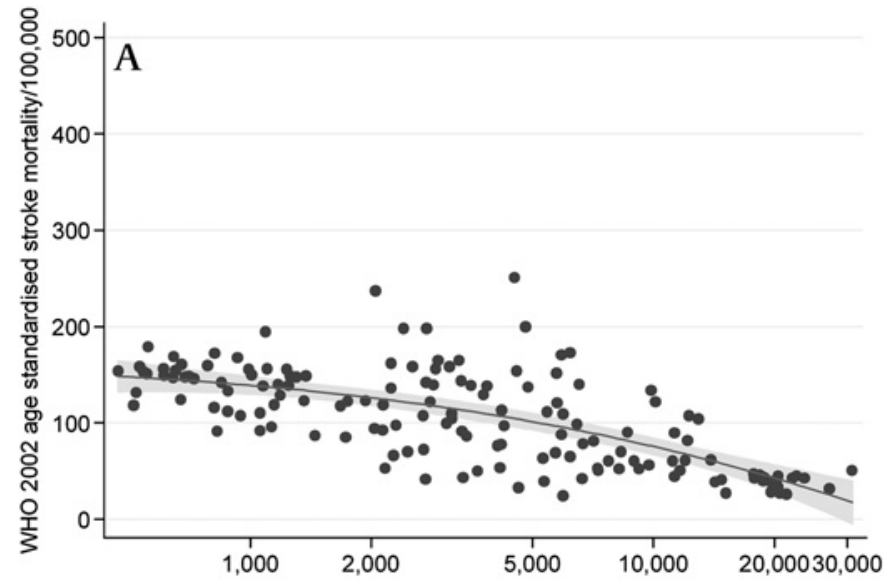

GDP/head in 1998 (1990 purchasing parity dollars)

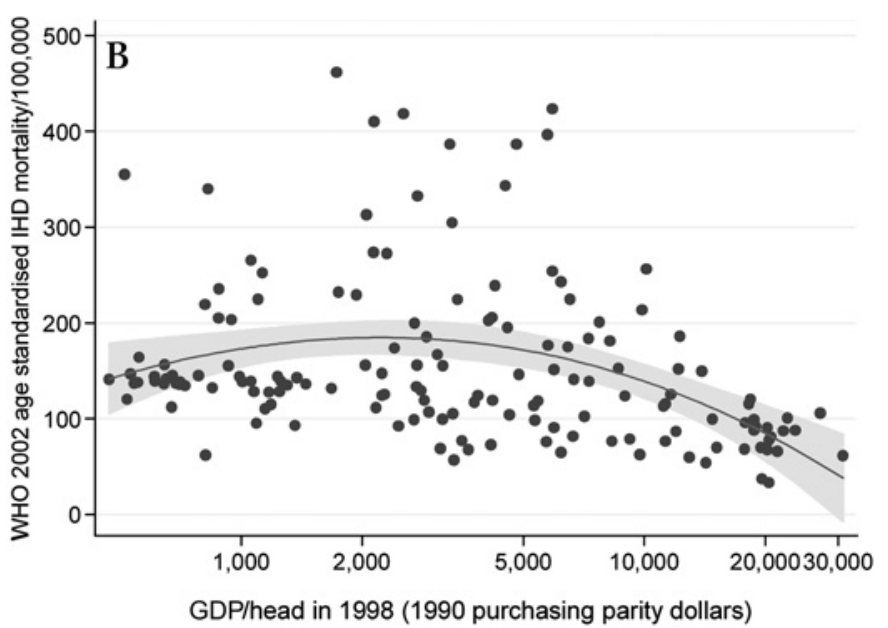

Figure 1 Mortality from stroke (left) and ischaemic heart disease (IHD) (right) by national income (gross domestic product (GDP) per capita).

curvilinear relationships (as shown), obtained using fractional polynomials, captured the associations better than purely linear relationships. Morbidity is shown in preference to mortality for diabetes, because diabetes is not usually recorded as the cause of death.

Stroke mortality is consistently negatively associated with national income, with possibly a stronger association at higher levels of national income. In contrast, low levels of national income are positively, albeit weakly, associated with IHD and diabetes, which changes to a negative association at medium to high levels for IHD and diabetes. Similarly, biological risk factors, such as cholesterol or obesity are positively associated with national income at low income levels, but negatively at high levels, whereas blood pressure has little clear association with national income. ${ }^{14} 15$

\section{Disparities within countries}

Somewhat similar to between country disparities, within countries at an individual level there is often a reverse social gradient at low levels of national income and the usual negative association between disease and socio-economic position at high levels of national income for $\mathrm{IHD}^{16-23}$ and diabetes. ${ }^{24-37}$ Moreover, there often appears to be a more marked reverse gradient for men, which is evident at higher levels of national income for IHD. ${ }^{16}$ 38-41 There are also similar patterns for biological risk factors, such as obesity ${ }^{1542} 43$ and hypertension, ${ }^{44} 45$ with again a more marked reverse gradient among men for obesity. ${ }^{15} 4243$

Overall, it appears that the pattern of disparities may vary by disease and sex as well as changing over epidemiological time, with stroke perhaps having the most consistent association with poverty. However, global disparities between and within countries are limited by being inevitably contemporaneous, hence the need to consider trends over time.

\section{HISTORICAL CONTEXT \\ Secular trends}

Congruent with the disease-specific patterns of disparities between countries by national income, there appear to be disease-specific secular trends accompanying economic development over historical time, that is, with epidemiological time. First, the epidemiological transition of stroke usually involves two opposite trends; haemorrhagic stroke declines, whereas ischaemic stroke increases. This trend was observed for stroke mortality over the 20th century in a long-term developed country, the $\mathrm{UK},{ }^{46}$ and more recently for stroke morbidity in one of the most developed areas of a rapidly developing country, Beijing, China. ${ }^{47}$ Second, recent economic development (via economic growth or migration) appears to be associated with diabetes in men and women, with little change in the sex ratio over time. ${ }^{48}$ This is currently the case in Asia, with its history of recent economic development. ${ }^{49}$ It is also evident for migrants from economically less to more developed locations, such as Hispanics in the USA ${ }^{50}$ or southern Europeans in Australia. ${ }^{51}$ Whether such an epidemic is a permanent attribute of that population or the product of history is difficult to ascertain. It is perhaps noteworthy that following the Jewish exodus from Russia in the late 19th century to the north-eastern US cities, Jews were in the early 20th century transiently more prone to diabetes. ${ }^{52} 53$ Third, the increase in IHD mortality only occured after many decades of economic development. In the USA and the UK economic growth started in the late 18th century, ${ }^{11} 54$ but only in the early 20th century did an epidemic of IHD take place. ${ }^{55}$ Similarly, in sub-Saharan Africa, in some Chinese populations with a short history of economic development and in first generation migrants from economically less to more developed locations, IHD has not risen strongly, although

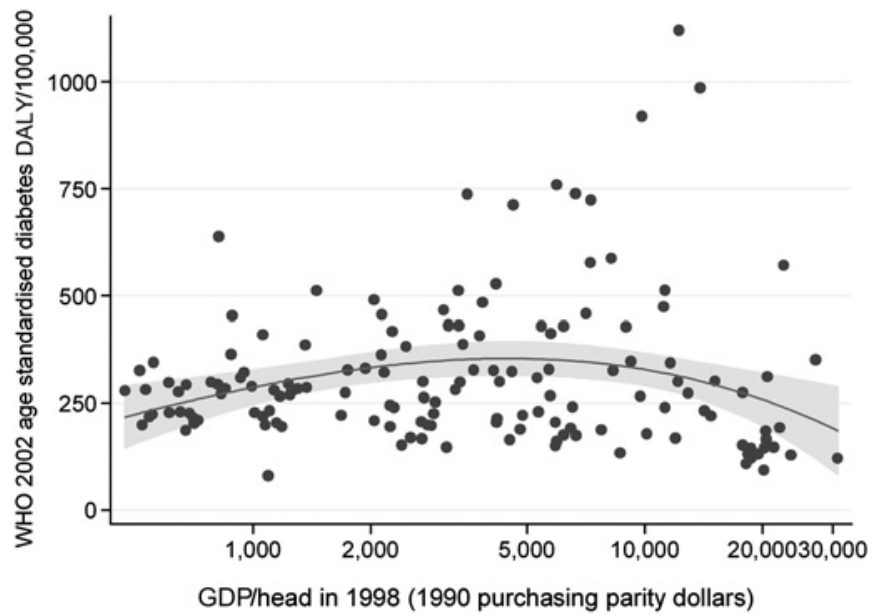

Figure 2 Morbidity from diabetes (disability adjusted life years (DALYs)) by national income (gross domestic product (GDP) per capita). 
diabetes has. ${ }^{57-61}$ Moreover, when this epidemic of premature IHD does occur, it is usually limited to men, ${ }^{55}$ for reasons that are unclear.

Coincident with these secular trends in disease patterns with epidemiological time, there are also long-term, though not simultaneous, secular trends towards greater height, ${ }^{62}$ larger frame size ${ }^{63}$ and earlier age at sexual maturity. ${ }^{62} 64$ Greater height, and particularly longer legs, is usually associated with lower risk of common non-communicable diseases, such as stroke, diabetes and IHD. ${ }^{65-80}$ However, again these associations appear to vary with disease and epidemiological time. Congruent with the consistent negative association between stroke and national income, this negative association is most consistent for stroke, ${ }^{65-70}$ and less consistent for diabetes, IHD or its component risk factors, ${ }^{68-70} 81-85$ particularly in populations with a short history of economic development. Height also has incoherent associations with IHD at individual and population levels.

\section{Disparities over historic time}

In contrast to the secular trends observed over epidemiological time since the start of economic development, information concerning changes over historical time is less well documented and may relate to periods preceding economic development when the infrastructure to collect such information was not in place. Health disparities are usually considered to have been consistent over historical time, ${ }^{86}$ although their extent in Europe before the start of the Industrial Revolution is unclear, ${ }^{86}$ and virtually unknown elsewhere. However, disease-specific secular trends alone would be expected to produce varying patterns of disparities. Historical evidence concerning disparities is limited. Nevertheless, consistent with the change in the pattern of disparities with epidemiological time, there is some evidence that racial and socio-economic disparities have changed over historic time. Diabetes was well known in Europe and the USA in the 19th century. At the end of the 19th century black people in the USA had lower rates of diabetes than white people, ${ }^{53}$ a reversal of the current situation. ${ }^{53}$ In the 20th century, the pattern of social disparities in male IHD reversed from an association with higher social position to an association with lower social position, ${ }^{87}$ although this initial positive association between IHD and social advantage could have been the result of systematically differential diagnosis. ${ }^{88}$ However, there is less evidence that this reversal took place for women, ${ }^{88}$ consistent with the lack of an epidemic of IHD in women at the later stages of economic development. ${ }^{55}$

\section{EXPLANATIONS}

There are several explanations commonly given for the incoherence of individual-level and between-population disparities in these diseases, globally and historically with economic development. Global disparities may be explained by genetic differences, the thrifty genotype ${ }^{89}$ or the thrifty phenotype. ${ }^{90}$ To date, the genetics of diabetes and IHD are still being explored. ${ }^{91-93}$ Promising candidate genes have been found, mainly among European populations, although whether these also explain global disparities is not yet known. In contrast, there is less genetic evidence for the thrifty phenotype hypothesis, ${ }^{94} 95$ which has also been challenged from anthropological ${ }^{96}$ and racial $^{97}$ perspectives. Moreover, genetic explanations do not provide any insight into disparities within countries. It is also unlikely that the disadvantaged are also genetically disposed towards these diseases. Arguably the disadvantaged might be more liable to environmental change over their lifetimes, making them more vulnerable to environmental 'mismatch' with its hypothesised consequences. ${ }^{98}$ However, evidence for that hypothesis mainly comes from small animals. ${ }^{99-101}$ In humans, social mobility, which equates to life course mismatched environments, carries no risk for cardiovascular disease beyond that of its component parts. ${ }^{102}$

Reversals in the social gradient of disease with economic development over historical time are usually explained in terms of inequalities in access to the benefits of economic development and changing social constructs of the value of body size. In lowincome countries, access to the lifestyle (more food, smoking, physical inactivity) associated with cardiovascular disease or diabetes may be restricted to the advantaged, giving a reverse social gradient, which later reverses as the benefits of economic development spread to less advantaged sections of populations. Similarly, in low-income countries larger, and fatter, body sizes may be valued when restricted to the more advantaged, but less valued when more widely accessible. Moreover, these social constructs and social norms concerning body size may be different for men and women, such that the social gradient changes more quickly for women than men. Finally, lifestyle changes in diet and physical activity with economic development may have a more immediate impact on glucose metabolism and diabetes than on IHD. The weaknesses with an explanation essentially premised on access to resources and social constructs are fivefold. First, the pattern of these diseases is heterogeneous over epidemiological time, necessitating a specific, but as yet unknown, sequence of lifestyle changes. Second, the pattern of change with epidemiological time varies with sex, necessitating sex-specific changes in lifestyle perhaps driven by changing social constructs of body shape. However, in long-term developed countries some of these changes took place largely before the current epidemic of obesity. Third, these diseases may share risk factors, but that does not imply they share causes. Fourth, this explanation in terms of lifestyle gives no insight into why there have been extended secular trends over time. Fifth, a lifestyle explanation may also imply that a common infection does not underlie social disparities, because the same group of people, most likely, are the first ones in their societies to experience socio-economic development with access to associated amenities (including running water) and to experience diabetes and heart disease, suggesting that infection is an unlikely causative agent, although more plausibly so for haemorrhagic stroke.

Other possible reasons for the incoherence of individual-level and between-population disparities globally and historically may provide insight into how disparities have originated and more importantly can be prevented, particularly in the developing world. It is becoming increasingly evident that there may be non-genomic biological mechanisms that transmit environmental influences on health across generations, that is, intergenerational effects. Such mechanisms provide a framework that would generate changes over many generations, with patterns of health varying with the number of generations since the start of economic development (eg, the Industrial Revolution or other similar watershed developmental milestones in more recently developed or developing economies), because of the long-range effect of living conditions in earlier generations. Such intergenerational effects would also generate effects contingent on the stage of the epidemiological transition. Below, it is tentatively suggested how framing within a historical context, including intergenerational effects, may provide fresh insights concerning disparities in some major non-communicable chronic diseases. 


\section{A socio-biological thesis}

Well-documented and extended changes over epidemiological time in height, frame size and build suggest that consideration of intergenerationally and environmentally driven changes during growth to the associated somatotrophic and gonadotrophic axes might provide a starting point for a socio-biological explanation of long-range changes in chronic diseases. Moreover, any associated differences in chronic disease risk factors at the termination of growth would be expected to track into adult life. ${ }^{103}$ The biological mechanisms underlying intergenerational changes to these axes are not yet entirely clear, although the recent rediscovery of non-Mendelian heritable changes in gene expression driven by the environment in previous generations, that is, epigenetics, provides a candidate. Moreover there also appears to be some preliminary evidence that intergenerational growth conditions may permanently upregulate offspring hormone levels. ${ }^{104-107}$ Similarly, hormone levels appear to increase with epidemiological time. ${ }^{107-109}$ Very speculatively, figure 3 shows schematically how the same exposure (improved living conditions over generations or historical time) might act on different biological axes (somatotrophic vs gonadotrophic) to generate specific patterns of diseases and disparities over epidemiological time.

\section{Somatotrophic axis}

Epigenetic mechanisms evolved to maximise maternal-offspring coadaptations, including regulation of postnatal growth. ${ }^{110} 111$ Different mechanisms control prepubertal and pubertal linear growth. ${ }^{112}$ When conditions allow, constrained prepubertal growth is usually followed by greater pubertal linear growth. ${ }^{113}$ In a developing or recently developed population, pubertal growth may respond immediately to better living conditions but leg length only responds over generations. ${ }^{62}{ }^{63}$ Relatively or absolutely more pubertal linear growth is associated with diabetes and/or insulin resistance, ${ }^{80} 85114$ most likely due to changes in the somatotrophic axis, that is, on insulin-like growth factor/growth hormone. These effects could be exacerbated by lack of compensating muscle mass from longer legs and larger frames.

In this socio-biological historical framework, the first generation to experience better living conditions during growth could be more vulnerable to diabetes because of compensatory growth at puberty. That first generation will have a reverse social gradient in diabetes, as those who did not experience improved conditions would have no compensatory growth at puberty.
Such a pattern has been seen in populations with a very recent history of economic development over one generation, such as China, ${ }^{27}$ India, ${ }^{28}{ }^{29}$ Bangladesh, $^{30}$ Pakistan $^{32}$ or Eygpt. ${ }^{34}$ However, this reverse gradient 'wears off' with generations of economic development, as maternal constraint wears off, as for example seen in the Chinese population of Hong Kong, who have a slightly longer history of economic development over one or two generations, ${ }^{35}$ or in some countries in South America ${ }^{36} 37$ with again a slightly longer history of economic development. ${ }^{11}$ When most people in the population have several generations of economic development behind them the usual social gradient in diabetes is seen. ${ }^{24} 115$ Moreover, all else being equal, rates of diabetes would be lower in long-term developed populations than in populations in transition. However, the countervailing forces of ageing/survivorship and contemporaneous environment in long-term developed countries are currently conspiring to keep population rates of diabetes persistently high. Nevertheless, currently, diabetes prevalence in the recently transitioned populations of Asia outstrips rates seen in long-term developed Western populations. ${ }^{49}$ Thus, epigenetic constraint combined with varying levels and histories of economic development may potentially generate disparate patterns of disparities within countries and a disparate pattern of diabetes with national income, because of higher rates of diabetes in rapidly transitioning (and usually middle income) populations.

\section{Gonadotrophic axis}

Sex-specific pubertal changes have previously been suggested as contributing to the earlier development of IHD in men, ${ }^{116}$ because pubertal sex-steroids act on key IHD risk factors. Pubertal sex-steroids reduce lower HDL cholesterol and increase android fat patterning in boys, with the opposite effects in girls. ${ }^{116-128}$ Diabetes risk is less sex-specifically affected by pubertal sex-steroids. ${ }^{124-128}$ Whether sexual dimorphism in blood pressure also arises at puberty, ${ }^{129}{ }^{130}$ similarly due to the action of sex-steroids is less clear. These pubertal changes have generally been assumed to be a universal environmentally independent feature of growth and development. However, sexdifferences in HDL cholesterol are contextually specific, suggesting environmental influences. ${ }^{131}$ Moreover, experimental evidence suggests that pubertal sex-steroids are dietary and possibly intergenerationally driven; in animals underfeeding reduces testosterone $e^{132-134}$ and oestrogen ${ }^{135}$ at puberty. Even in universally well-fed human populations in the West, slight changes in diet affect sex-steroids in girls ${ }^{136}$ but not in boys, ${ }^{137}$
Figure 3 Schematic outline of how socio-historical processes have biological effects on non-communicable chronic diseases over epidemiological time. IHD, ischaemic heart disease.

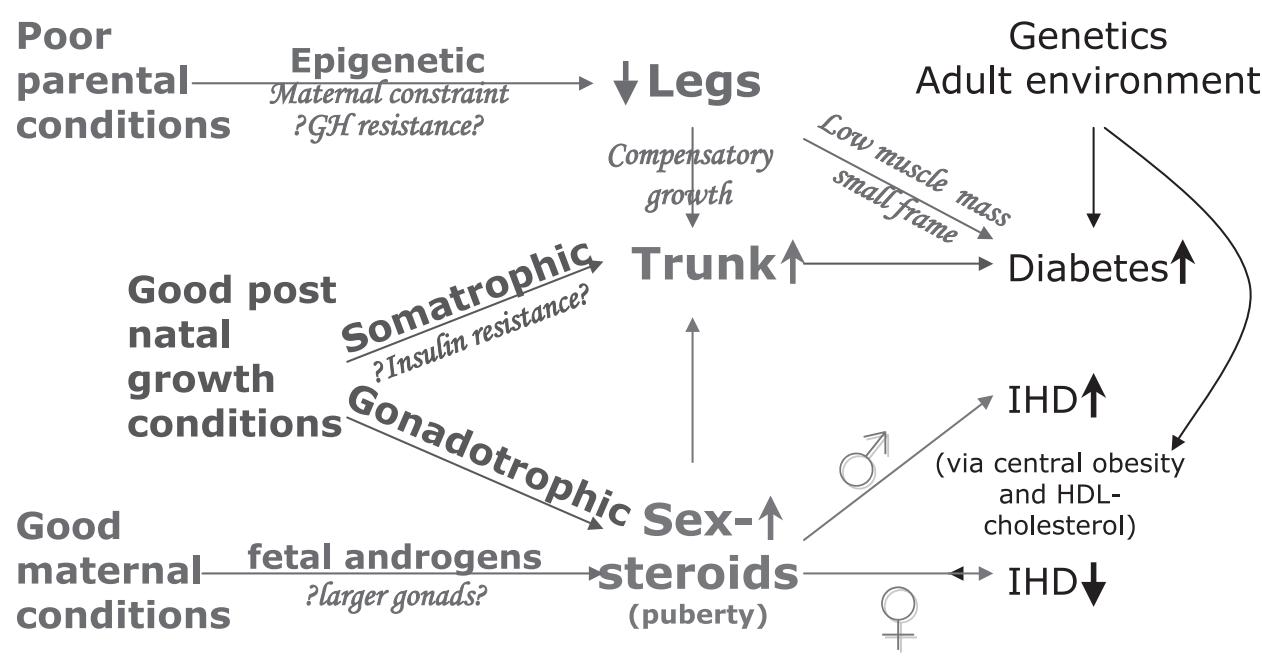


although larger changes between environments may make a difference. ${ }^{138}$ In rats, maternal food restriction during late pregnancy and lactation drastically reduces testicular size ${ }^{139}$ with potential consequences at puberty. As would be expected from a dietary-driven process, the pattern of pubertal development is different in developed environments ${ }^{140}$ as opposed to very poor environments, ${ }^{138}$ and has changed over historical time. ${ }^{141}$

In this alternative, less Western-centric, conceptualisation, economic development permanently upregulates the gonadotrophic axis via pubertal nutrition with corresponding intergenerational effects. Higher levels of pubertal sex-steroids have sex-specific effects on IHD mediated by central obesity and lipids. Hence, a sex-specific pattern of disparities in IHD would be expected to emerge with economic development. As with diabetes, in the early stages of economic development it is likely to be the advantaged who are initially at increased risk of IHD, hence the reverse gradient in IHD observed for men but less so in women. ${ }^{1688}$ This sexually dimorphic pattern of social disparities in IHD, obesity and/or lipids, but not diabetes, in the first few generations to experience economic development has been observed in a recent study from a developing population, ${ }^{142}$ where the generally protective effect of social advantage was obscured for these risk factors in men. Similarly, there are many studies from long-term developed countries showing a usually unexplained or weaker social gradient for men than women in obesity, lipids and IHD, ${ }^{15} 163940$ with particularly marked differences in disparities by sex for populations at an earlier stage of economic development or with a shorter history of economic development. ${ }^{38} 41$ Finally, the implication of this conceptualisation is that higher IHD mortality in men is partly an epidemiologically stage-specific product of growth in an economically developed environment. Seminal epidemiological studies in the 1970s of Japanese men who had migrated to the USA found that 'Westernisation' during childhood was a key exposure driving IHD. ${ }^{143} 144$ More recent studies of migration within China have replicated these observations and indicated that they are specific to men. ${ }^{145-147}$ Vulnerability to premature IHD in men may not be an immutable sex difference, but a disparity resulting from socio-economic development.

\section{LIMITATIONS}

Although this conceptualisation uses largely known physiological evidence to provide a socio-biological explanation for the observed trends in aggregate and disaggregated disparities in some major non-communicable chronic diseases, key gaps and limitations remain. First, the biological basis for the epigenetic mechanisms that constrain infant and childhood growth have yet to be mapped out, although there is epidemiological evidence of such constraint. ${ }^{148-151}$ Second, it is a supposition that these epigenetic mechanisms act via the somatotrophic axis; however, growth hormone is more important to prepubertal than pubertal growth. ${ }^{152}$ Third, it is not clear in this framework why improved living conditions in the first generation should have less effect on IHD, obesity and lipids than on diabetes. However, in that first generation there would not be any additional contribution to the gonadotrophic axis from maternal hormone levels and it is possible that differences in the somatotrophic axis may alter the tempo of pubertal development. ${ }^{153}$ Fourth, it is also largely unknown how maternal sex-steroids may affect pubertal sex-steroids in her offspring. Fifth, this framework provides no insight about a key risk factor for non-communicable chronic diseases, that is blood pressure, because it is not clear how blood pressure fits into this framework. There is no clear global pattern to blood pressure. ${ }^{14}$ Biologically and epide- miologically it is not clear how blood pressure is affected by puberty. ${ }^{129} 130142$ Sixth, this conceptualisation has not considered the effects of interplays between the somatotrophic and gonadotrophic axes during growth, such as upregulation of the gonadotrophic axis increasing peak pubertal mass muscle mass and thereby reducing the long-term risk of diabetes. ${ }^{154}$ Seventh, intergenerational upregulation of the gonadotrophic axis with epidemiological time would be expected to have many other impacts on population health and disparities because of the pleiotrophic effects of pubertal sex-steroids. Intergenerational increases in pubertal sex-steroids could underlie other features of the epidemiological transition, such as higher rates of female hormonally related cancers mediated by oestrogen. ${ }^{155}$ Similarly, higher levels of pubertal sex-steroids would be expected to have sex-specific immunomodulatory effects possibly making men more vulnerable to inflammation and infection, ${ }^{156}$ possibly with lifelong effects. Eighth, it is quite possible that with economic development and the associated socially patterned reductions in infectious diseases and increases in life expectancy, the relationship between acute and chronic diseases may itself drive some of the patterns of disparities in chronic diseases. However, it is not obvious why socially patterned survival should produce disease or sex-specific disparities, nevertheless such a possibility cannot be ruled out. Ninth, the present theoretical framework does not provide direct insight into the processes that are currently generating associated epidemics of obesity and diabetes in long-term developed countries, because the focus is aimed at explaining the pattern of social disparities and disease that emerges with economic development. As such the present framework may be most relevant to developing countries, especially those undergoing rapid change. Finally, this conceptualisation in no way negates the multidimensional role of deprivation in generating disparities. Instead, this conceptualisation simply seeks to add a dimension across time and to draw attention to the off-diagonals to generate new hypotheses. For example, it suggests that one exposure (improved living conditions over generations) has long-term effects on two different biological axes. Coincident changes to these two axes may generate a myriad of non-causal associations.

Several of the limitations concerning the hypothesised biological mechanisms could be addressed by a research programme using animal models supplemented by observations of adolescents. To the authors' knowledge, no previous study has monitored in small animals, taken from a constrained environment, what changes in size, build, metabolic parameters, immune function and to the gonadotrophic and somatotrophic axes occur with each successive generation of exposure to a more 'Westernised' environment for a varying number of generations. Such an experiment would test the present hypothesis by mimicking different trajectories of economic development over a fairly short timescale. Alternatively, tracking size, muscle mass, metabolic parameters, immune function and sex-steroids through puberty in a well-characterised birth cohort whose members had different family histories of economic development would also provide insights within a reasonably short timescale. Furthermore, evidence from such studies could be used to inform policies to reduce disparities.

\section{Public health implications}

This conceptualisation represents a move away from black box risk factor epidemiology, with its tangled web of associations, towards a more aetiological approach and thus the prospect of more focused interventions with potentially a better understanding of any unintended consequences. Most obviously, it 
focuses attention on puberty as a key window of intervention to prevent disparities arising. However, it also suggests that one generic intervention will not necessarily have similar effects across all non-communicable chronic diseases. Instead, any intervention should be grounded in a contextually specific assessment of which non-communicable chronic disease is forecast to be most salient for the current generation of children, backed up by a detailed assessment of their current living conditions and any potential impacts on long-term health. Specifically, a comparative examination of the effect of pubertal nutrition on body composition and chronic disease risk factors in children growing up in the developing world would be informative. Moreover, it is also quite possible that such an assessment may indicate that sex or disease-specific policies are warranted, for example, a focus on boys or lifelong diabetes prevention may have the greatest impact. Systematic surveillance programmes monitoring children's lifestyle and health in developing countries, alongside focused investigation of specific hypotheses, by global organisations, such as the WHO, would contribute to the global evidence base for development. As always, countries supporting the economic development of developing populations should carefully assess, a priori, the anticipated impact of their policies on long-term health and tailor their interventions to generate an environment that promotes optimal child growth. Although it may be tempting or even justified after thorough deliberation that, in the short-term, economic growth and associated gains in life expectancy could or should be traded off against disparities and the long-term health of today's children, such calculus must be made explicitly and honestly based on a full understanding of potential environmental impact during growth. Finally, the authors caution that one must be mindful that the theoretical construct as presently proposed requires further epidemiologic confirmation and laboratory-based validation, before it should be relied on to formulate large-scale interventions or policies. Given these considerations and the changes in nutrition and physical activity that have already occurred in some developing countries, immutable changes in risk may have already taken place, which perhaps need to be addressed by healthcare provision as well as prevention.

\section{CONCLUSION}

Despite its tentative and speculative nature, taking a broad brush approach, this study demonstrates the value of framing non-communicable chronic disease disparities within a global and historical perspective. It also implies that evidence from the Western world at its particular epidemiological stage is insufficient to interpret the global pattern of disparities, because patterns of disparities are epidemiologically stagespecific. As such, mounting evidence from the developed world is largely uninformative for the developing world, and instead there is an ethical imperative to focus research efforts on developing countries. In particular, examination of southsouth, rather than north-south, similarities and contrasts, may be uniquely informative in identifying how economic transition can be achieved while minimising social disparities. Perhaps most importantly from a practical point of view, further investigation of the role of pubertal exposures in the development of IHD and diabetes is urgently needed, so that the long-term consequences of the nutrition transition across life can be assessed and any potential risks averted before irrevocable changes have taken place throughout the developing world.

\section{What is already known on this subject}

Social disparities in health are pervasive and persistent.

- There is some evidence that social disparities in some non-communicable chronic diseases may vary with epidemiological stage or level of socio-economic development.

\section{What this study adds}

- This study places social disparities in some non-communicable chronic diseases within a global and historical perspective.

- It provides epigenetic, physiological and epidemiological evidence for a tentative socio-biological explanation for some of the changes observed with economic development.

- It draws attention to potential long-range effects on social disparities in health over historical and epidemiological time, and hence the need to ensure that policies to combat such disparities are contextually specific.

\section{Competing interests None.}

Provenance and peer review Not commissioned; externally peer reviewed.

\section{REFERENCES}

1. Adler NE, Rehkopf DH. U.S. disparities in health: descriptions, causes, and mechanisms. Annu Rev Public Health 2008;29:235-52.

2. Krieger N, Rehkopf DH, Chen JT, et al. The fall and rise of US inequities in premature mortality: 1960-2002. PLoS Med 2008;5:e46.

3. Department of Health and Social Security. Inequalities in health. London: DHSS, 1980.

4. Final report of the Commission on Social Determinants of Health. WHO commission on social determinants of health. Closing the gap in a generation: health equity through action on the social determinants of health. Geneva: WHO, 2008.

5. Lynch JW, Smith GD, Kaplan GA, et al. Income inequality and mortality: importance to health of individual income, psychosocial environment, or material conditions. BMJ 2000;320:1200-4.

6. Siegrist J, Marmot M. Health inequalities and the psychosocial environment-two scientific challenges. Soc Sci Med 2004;58:1463-73.

7. Subramanian SV, Belli $P$, Kawachi I. The macroeconomic determinants of health Annu Rev Public Health 2002:23:287-302.

8. Wilkinson RG, Pickett KE. The problems of relative deprivation: why some societies do better than others. Soc Sci Med 2007;65:1965-78.

9. Zimmerman FJ. A commentary on "neo-materialist theory and the tempora relationship between income inequality and longevity change". Soc Sci Med 2008:66:1882-94.

10. Mathers CD, Loncar D. Projections of global mortality and burden of disease from 2002 to 2030. PLoS Med 2006;3:e442.

11. Maddison A. Development centre studies: the world economy: historical statistics. Paris: OECD, 2003

12. WHO mortality. http://www.who.int/research/en/ (accessed Sep 2008)

13. WHO obesity. http://www.who.int/bmi/index.jsp (accessed Sep 2008).

14. Ezzati M, Vander HS, Lawes CM, et al. Rethinking the "diseases of affluence" paradigm: global patterns of nutritional risks in relation to economic development. PLoS Med 2005:2:e133.

15. McLaren L. Socioeconomic status and obesity. Epidemiol Rev 2007;29:29-48.

16. Avendano M, Kunst AE, Huisman M, et al. Socioeconomic status and ischaemic heart disease mortality in 10 western European populations during the 1990s. Heart 2006;92:461-7

17. Singh RB, Sharma JP, Rastogi V, et al. Prevalence of coronary artery disease and coronary risk factors in rural and urban populations of north India. Eur Heart $J$ 1997; 18:1728-35

18. Steyn K, Sliwa K, Hawken S, et al. Risk factors associated with myocardial infarction in Africa: the INTERHEART Africa study. Circulation 2005;112:3554-61.

19. Chang CL, Marmot MG, Farley TM, et al. The influence of economic development on the association between education and the risk of acute myocardial infarction and stroke. J Clin Epidemiol 2002;55:741-7.

20. Singh RB, Niaz MA, Thakur AS, et al. Social class and coronary artery disease in a urban population of North India in the Indian Lifestyle and Heart Study. Int J Cardiol 1998;64:195-203. 
21. Singh RB, Niaz MA, Ghosh $\mathrm{S}$, et al. Epidemiological study of coronary artery disease and its risk factors in an elderly urban population of North India. J Am Coll Nutr 1995;14:628-34.

22. Chadha SL, Gopinath N, Ramachandran K. Epidemiological study of coronary heart disease in Gujaratis in Delhi (India). Indian J Med Res 1992;96:115-21.

23. Malhotra SL. Epidemiology of ischaemic heart disease in India with special reference to causation. Br Heart J 1967;29:895-905.

24. Dalstra JA, Kunst AE, Borrell C, et al. Socioeconomic differences in the prevalence of common chronic diseases: an overview of eight European countries. Int $J$ Epidemiol 2005;34:316-26.

25. Lidfeldt J, Li TY, Hu FB, et al. A prospective study of childhood and adult socioeconomic status and incidence of type 2 diabetes in women. Am J Epidemiol 2007; 165:882-9

26. Ramachandran A, Mary S, Yamuna A, et al. High prevalence of diabetes and cardiovascular risk factors associated with urbanization in India. Diabetes Care 2008;31:893-8

27. $\mathbf{X u} \mathbf{F}$, Yin $\mathbf{X M}$, Zhang $\mathbf{M}$, et al. Family average income and diagnosed Type 2 diabetes in urban and rural residents in regional mainland China. Diabet Med 2006;23:1239-46.

28. Ram R, Goswami DN, Bhattacharya SK, et al. An epidemiological study on risk factors of diabetes mellitus among patients attending a medical college hospital in Kolkata, West Bengal. J Indian Med Assoc 2006;104:428-30.

29. Mohan V, Shanthirani CS, Deepa R. Glucose intolerance (diabetes and IGT) in a selected South Indian population with special reference to family history, obesity and lifestyle factors-the Chennai Urban Population Study (CUPS 14). J Assoc Physicians India 2003;51:771-7.

30. Sayeed MA, Mahtab H, Akter KP, et al. Diabetes and impaired fasting glycemia in a rural population of Bangladesh. Diabetes Care 2003:26:1034-9.

31. Singh RB, Beegom R, Mehta AS, et al. Social class, coronary risk factors and undernutrition, a double burden of diseases, in women during transition, in five Indian cities. Int J Cardiol 1999:69:139-47.

32. Hameed K, Kadir M, Gibson T, et al. The frequency of known diabetes, hypertension and ischaemic heart disease in affluent and poor urban populations of Karachi, Pakistan. Diabet Med 1995:12:500-3.

33. Ali 0, Tan TT, Sakinah 0, et al. Prevalence of NIDDM and impaired glucose tolerance in aborigines and Malays in Malaysia and their relationship to sociodemographic, health, and nutritional factors. Diabetes Care 1993;16:68-75.

34. Herman WH, Ali MA, Aubert RE, et al. Diabetes mellitus in Egypt: risk factors and prevalence. Diabet Med 1995;12:1126-31.

35. Ko GT, Chan JC, Yeung VT, et al. A low socio-economic status is an additional risk factor for glucose intolerance in high risk Hong Kong Chinese. Eur J Epidemiol 2001;17:289-95.

36. Theme-Filha MM, Szwarcwald CL, Souza-Junior PR. Socio-demographic characteristics, treatment coverage, and self-rated health of individuals who reported six chronic diseases in Brazil, 2003. Cad Saude Publica 2005;(Suppl 21):43-53.

37. Goldstein J, Jacoby E, del AR, et al. Poverty is a predictor of non-communicable disease among adults in Peruvian cities. Prev Med 2005;41:800-6.

38. Maddah M, Chinikar M, Hoda S. Educational characteristic of Iranian patients with coronary artery disease. Int J Cardiol 2007;115:412-13.

39. Loucks EB, Rehkopf DH, Thurston RC, et al. Socioeconomic disparities in metabolic syndrome differ by gender: evidence from NHANES III. Ann Epidemiol 2007:17:19-26.

40. Thurston RC, Kubzansky LD, Kawachi I, et al. Is the association between socioeconomic position and coronary heart disease stronger in women than in men? Am J Epidemiol 2005;162:57-65.

41. Kim MH, Kim MK, Choi BY, et al. Educational disparities in the metabolic syndrome in a rapidly changing society-the case of South Korea. Int $J$ Epidemiol 2005:34:1266-73.

42. Sobal J, Stunkard AJ. Socioeconomic status and obesity: a review of the literature. Psychol Bull 1989;105:260-75

43. Monteiro CA, Moura EC, Conde WL, et al. Socioeconomic status and obesity in adult populations of developing countries: a review. Bull World Health Organ 2004:82:940-6.

44. Colhoun HM, Hemingway H, Poulter NR. Socio-economic status and blood pressure: an overview analysis. J Hum Hypertens 1998;12:91-110.

45. Fernald LC, Adler NE. Blood pressure and socioeconomic status in low-income women in Mexico: a reverse gradient? J Epidemiol Community Health 2008;62:e8.

46. Lawlor DA, Smith GD, Leon DA, et al. Secular trends in mortality by stroke subtype in the 20th century: a retrospective analysis. Lancet 2002;360 1818-23.

47. Zhao D, Liu J, Wang W, et al. Epidemiological transition of stroke in China: twenty-one-year observational study from the Sino-MONICA-Beijing Project. Stroke 2008;39:1668-74.

48. Gale EA, Gillespie KM. Diabetes and gender. Diabetologia 2001;44:3-15.

49. Chan JC, Malik V, Jia W, et al. Diabetes in Asia: epidemiology, risk factors, and pathophysiology. JAMA 2009;301:2129-40.

50. Cowie CC, Rust KF, Ford ES, et al. Full accounting of diabetes and pre-diabetes in the U.S. population in 1988-1994 and 2005-2006. Diabetes Care 2009:32:287-94

51. Kouris-Blazos A. Morbidity mortality paradox of 1st generation Greek Australians. Asia Pac J Clin Nutr 2002;11(Suppl 3):S569-75.
52. Bolduan C, Weiner L. Causes of death among Jews in New York City. NEJM 1933;208:407-16.

53. Humphreys $\mathbf{M}$, Costanzo P, Haynie $\mathrm{KL}$, et al. Racial disparities in diabetes a century ago: evidence from the pension files of US Civil War veterans. Soc Sci Med 2007;64:1766-75.

54. Clark G. A farewell to alms: a brief economic history of the world. Princeton, New Jersey: Princeton University Press, 2007

55. Lawlor DA, Ebrahim S, Smith GD. Sex matters: secular and geographical trends in sex differences in coronary heart disease mortality. BMJ 2001:323:541-5.

56. Nikiforov SV, Mamaev VB. The development of sex differences in cardiovascular disease mortality: a historical perspective. Am J Public Health 1998;88:1348-53.

57. Smith DP, Bradshaw BS. Rethinking the Hispanic paradox: death rates and life expectancy for US non-Hispanic White and Hispanic populations. Am J Public Health 2006;96:1686-92.

58. Markides KS, Eschbach K. Aging, migration, and mortality: current status of research on the Hispanic paradox. J Gerontol B Psychol Sci Soc Sci 2005;60 Spec No 2:68-75.

59. Walker AR, Walker BF, Sci DD, et al. Variations in occurrences of nutrition-related diseases in Sub-Saharan Africans in stages of transition: what of the future? Nutrition 2002;18:71-4.

60. Janus ED, Watt NM, Lam KS, et al. The prevalence of diabetes, association with cardiovascular risk factors and implications of diagnostic criteria (ADA 1997 and WHO 1998) in a 1996 community-based population study in Hong Kong Chinese. Hong Kong Cardiovascular Risk Factor Steering Committee. American Diabetes Association. Diabet Med 2000:17:741-5.

61. Dwyer T, Emmanuel SC, Janus ED, et al. The emergence of coronary heart disease in populations of Chinese descent. Atherosclerosis 2003:167:303-10.

62. Cole TJ. The secular trend in human physical growth: a biological view. Econ Hum Biol 2003;1:161-8.

63. Himes JH. Secular changes in body proportions and composition. Monogr Soc Res Child Dev 1979;44:28-58.

64. Karlberg J. Secular trends in pubertal development. Horm Res 2002;57(Suppl 2):19-30.

65. Njolstad I, Arnesen E, Lund-Larsen PG. Body height, cardiovascular risk factors, and risk of stroke in middle-aged men and women. A 14-year follow-up of the Finnmark Study. Circulation 1996;94:2877-82.

66. Davey SG, Hart C, Upton M, et al. Height and risk of death among men and women: aetiological implications of associations with cardiorespiratory disease and cancer mortality. J Epidemiol Community Health 2000;54:97-103.

67. McCarron P, Okasha M, McEwen J, et al. Height in young adulthood and risk of death from cardiorespiratory disease: a prospective study of male former students of Glasgow University, Scotland. Am J Epidemiol 2002;155:683-7.

68. Goldbourt U, Tanne D. Body height is associated with decreased long-term stroke but not coronary heart disease mortality? Stroke 2002:33:743-8.

69. Song YM, Smith GD, Sung J. Adult height and cause-specific mortality: a large prospective study of South Korean men. Am J Epidemiol 2003;158:479-85.

70. Song YM, Sung J. Adult height and the risk of mortality in South Korean women. Am J Epidemiol 2008;168:497-505

71. Han TS, Feskens EJ, Lean ME, et al. Associations of body composition with type 2 diabetes mellitus. Diabet Med 1998;15:129-35.

72. Wamala SP, Mittleman MA, Horsten M, et al. Short stature and prognosis of coronary heart disease in women. J Intern Med 1999:245:557-63.

73. Forsen T, Eriksson J, Qiao 0 , et al. Short stature and coronary heart disease: a 35-year follow-up of the Finnish cohorts of the seven countries study. J Intern Med 2000;248:326-32.

74. Ferrie JE, Langenberg C, Shipley MJ, et al. Birth weight, components of height and coronary heart disease: evidence from the Whitehall II study. Int J Epidemiol 2006;35:1532-42.

75. Silventoinen K, Zdravkovic S, Skytthe A, et al. Association between height and coronary heart disease mortality: a prospective study of 35,000 twin pairs. Am J Epidemiol 2006;163:615-21.

76. Gunnell DJ, Smith GD, Frankel S, et al. Childhood leg length and adult mortality: follow up of the Carnegie (Boyd Orr) Survey of Diet and Health in Pre-war Britain. J Epidemiol Community Health 1998;52:142-52.

77. Smith GD, Greenwood R, Gunnell D, et al. Leg length, insulin resistance, and coronary heart disease risk: the Caerphilly Study. J Epidemiol Community Health 2001;55:867-72.

78. Langenberg C, Hardy R, Kuh D, et al. Influence of height, leg and trunk length on pulse pressure, systolic and diastolic blood pressure. J Hypertens 2003;21:537-43.

79. Lawlor DA, Taylor M, Davey SG, et al. Associations of components of adult height with coronary heart disease in postmenopausal women: the British women's heart and health study. Heart 2004;90:745-9.

80. Asao K, Kao WH, Baptiste-Roberts K, et al. Short stature and the risk of adiposity insulin resistance, and type 2 diabetes in middle age: the third National Health and Nutrition Examination Survey (NHANES III), 1988-1994. Diabetes Care 2006:29:1632-7.

81. Langenberg C, Shipley MJ, Batty GD, et al. Adult socioeconomic position and the association between height and coronary heart disease mortality: findings from 33 years of follow-up in the Whitehall study. Am J Public Health 2005;95:628-32. 
82. Liao Y, McGee DL, Cao G, et al. Short stature and risk of mortality and cardiovascular disease: negative findings from the NHANES I epidemiologic follow-up study. J Am Coll Cardiol 1996;27:678-82.

83. Kannan S, Nielsen SS, Mason AC. Protein digestibility-corrected amino acid scores for bean and bean-rice infant weaning food products. J Agric Food Chem 2001:49:5070-4.

84. Schooling CM, Thomas GN, Leung GM, et al. Is height associated with cardiovascular risk in Chinese? Epidemiology 2007;18:274-8.

85. Schooling CM, Jiang C, Lam TH, et al. Height, its components and cardiovascular risk in older Chinese: a cross-sectional analysis of The Guangzhou Biobank Cohort Study. Am J Public Health 2007;18:1834-41.

86. Kunitz SJ. Sex, race and social role-history and the social determinants of health. Int J Epidemiol 2007;36:3-10.

87. Gonzalez MA, Rodriguez AF, Calero JR. Relationship between socioeconomic status and ischaemic heart disease in cohort and case-control studies: 1960-1993. Int J Epidemiol 1998;27:350-8.

88. Smith GD. Life course approaches to socioeconomic differentials in health. In: Kuh D, Ben Shlomo Y, eds. A life course approach to chronic disease epidemiology. 2nd edn. Oxford: OUP, 2004:77-115

89. Neel JV. Diabetes mellitus: a "thrifty" genotype rendered detrimental by "progress"? Am J Hum Genet 1962;14:353-62.

90. Hales CN, Barker DJ. Type 2 (non-insulin-dependent) diabetes mellitus: the thrifty phenotype hypothesis. Diabetologia 1992;35:595-601.

91. Owen KR, McCarthy Ml. Genetics of type 2 diabetes. Curr Opin Genet Dev 2007:17:239-44.

92. Hamsten A, Eriksson P. Identifying the susceptibility genes for coronary artery disease: from hyperbole through doubt to cautious optimism. J Intern Med 2008:263:538-52.

93. Loos RJ, Bouchard C. FTO: the first gene contributing to common forms of human obesity. Obes Rev 2008;9:246-50.

94. Speakman JR. Thrifty genes for obesity and the metabolic syndrome-time to call off the search? Diab Vasc Dis Res 2006;3:7-11.

95. Prentice AM, Rayco-Solon P, Moore SE. Insights from the developing world: thrifty genotypes and thrifty phenotypes. Proc Nutr Soc 2005:64:153-61.

96. Benyshek DC, Watson JT. Exploring the thrifty genotype's food-shortage assumptions: a cross-cultural comparison of ethnographic accounts of food security among foraging and agricultural societies. Am J Phys Anthropol 2006;131:120-6.

97. Fee M. Racializing narratives: obesity, diabetes and the "aboriginal" thrifty genotype. Soc Sci Med 2006:62:2988-97.

98. Gluckman P, Hanson M. Mismatch: why our bodies no longer fit our world. Oxford: OUP, 2006.

99. Gluckman PD, Hanson MA, Pinal C. The developmental origins of adult disease. Matern Child Nutr 2005;1:130-41.

100. Gluckman PD, Hanson MA, Beedle AS. Early life events and their consequences for later disease: a life history and evolutionary perspective. Am J Hum Biol 2007; 19:1-19.

101. Fernandez-Twinn DS, Ozanne SE. Mechanisms by which poor early growth programs type-2 diabetes, obesity and the metabolic syndrome. Physiol Behav 2006;88:234-43.

102. Pollitt RA, Rose KM, Kaufman JS. Evaluating the evidence for models of life course socioeconomic factors and cardiovascular outcomes: a systematic review. BMC Public Health 2005;5:7.

103. Ovesen L. Adolescence: a critical period for long-term tracking of risk for coronary heart disease? Ann Nutr Metab 2006;50:317-24.

104. Nunez-De La MA, Bentley GR, Choudhury OA, et al. The impact of developmental conditions on adult salivary estradiol levels: why this differs from progesterone? Am J Hum Biol 2008;20:2-14.

105. Barker DJ, Osmond C, Thornburg KL, et al. A possible link between the pubertal growth of girls and breast cancer in their daughters. Am J Hum Biol 2008;20:127-31

106. Barker DJ, Osmond C, Thornburg KL, et al. A possible link between the pubertal growth of girls and ovarian cancer in their daughters. Am J Hum Biol 2008;20:659-62.

107. Nunez-de la MA, Chatterton RT, Choudhury OA, et al. Childhood conditions influence adult progesterone levels. PLoS Med 2007;4:e167.

108. Ellison PT, Bribiescas RG, Bentley GR, et al. Population variation in age-related decline in male salivary testosterone. Hum Reprod 2002:17:3251-3.

109. Ellison PT. Salivary steroids and natural variation in human ovarian function. Ann N Y Acad Sci 1994:709:287-98.

110. Wolf JB, Hager R. A maternal-offspring coadaptation theory for the evolution of genomic imprinting. PLoS Biol 2006; 4:e380.

111. Wood AJ, Oakey RJ. Genomic imprinting in mammals: emerging themes and established theories. PLoS Genet 2006;2:e147.

112. Karlberg J. On the modelling of human growth. Stat Med 1987;6:185-92

113. Luo ZC, Cheung YB, He 0, et al. Growth in early life and its relation to pubertal growth. Epidemiology 2003;14:65-73.

114. Lawlor DA, Ebrahim S, Davey SG. The association between components of adult height and Type II diabetes and insulin resistance: British Women's Heart and Health Study. Diabetologia 2002;45:1097-106

115. Kanjilal S, Gregg EW, Cheng YJ, et al. Socioeconomic status and trends in disparities in 4 major risk factors for cardiovascular disease among US adults, 1971-2002. Arch Intern Med 2006;166:2348-55
116. Berenson GS, Srinivasan SR, Cresanta JL, et al. Dynamic changes of serum lipoproteins in children during adolescence and sexual maturation. Am J Epidemiol 1981;113:157-70.

117. Srinivasan SR, Sundaram GS, Williamson GD, et al. Serum lipoproteins and endogenous sex hormones in early life: observations in children with different lipoprotein profiles. Metabolism 1985;34:861-7.

118. Arslanian S, Suprasongsin C. Testosterone treatment in adolescents with delayed puberty: changes in body composition, protein, fat, and glucose metabolism. J Clin Endocrinol Metab 1997:82:3213-20.

119. Kirkland RT, Keenan BS, Probstfield JL, et al. Decrease in plasma high-density lipoprotein cholesterol levels at puberty in boys with delayed adolescence. Correlation with plasma testosterone levels. JAMA 1987:257:502-7.

120. Roemmich JN, Rogol AD. Hormonal changes during puberty and their relationship to fat distribution. Am J Human Biol 1999:11:209-24.

121. Jaross W, Baehrecke $M$, Trubsbach $A$, et al. Effects of sexual maturation on serum lipoproteins. Endokrinologie 1981;78:28-34.

122. Stozicky F, Slaby P, Volenikova L. Longitudinal study of serum cholesterol, apolipoproteins and sex hormones during puberty. Acta Paediatr Scand 1991;80:1139-44.

123. Morrison JA, Barton BA, Biro FM, et al. Sex hormones and the changes in adolescent male lipids: Iongitudinal studies in a biracial cohort. $J$ Pediatr 2003;142:637-42

124. Wickman S, Saukkonen T, Dunkel L. The role of sex steroids in the regulation of insulin sensitivity and serum lipid concentrations during male puberty: a prospective study with a P450-aromatase inhibitor. Eur J Endocrinol 2002;146:339-46.

125. Hero M, Ankarberg-Lindgren C, Taskinen MR, et al. Blockade of oestrogen biosynthesis in peripubertal boys: effects on lipid metabolism, insulin sensitivity, and body composition. Eur J Endocrinol 2006;155:453-60.

126. Moran A, Jacobs DR Jr, Steinberger J, et al. Association between the insulin resistance of puberty and the insulin-like growth factor-l/growth hormone axis. J Clin Endocrinol Metab 2002;87:4817-20.

127. Goran MI, Gower BA. Longitudinal study on pubertal insulin resistance. Diabetes 2001:50:2444-50.

128. Saad RJ, Keenan BS, Danadian K, et al. Dihydrotestosterone treatment in adolescents with delayed puberty: does it explain insulin resistance of puberty? J Clin Endocrinol Metab 2001;86:4881-6.

129. Dasgupta K, O'Loughlin J, Chen S, et al. Emergence of sex differences in prevalence of high systolic blood pressure: analysis of a longitudinal adolescent cohort. Circulation 2006;114:2663-70.

130. Shankar RR, Eckert GJ, Saha C, et al. The change in blood pressure during puberta growth. J Clin Endocrinol Metab 2005:90:163-7.

131. Davis CE, Williams DH, Oganov RG, et al. Sex difference in high density lipoprotein cholesterol in six countries. Am J Epidemiol 1996;143:1100-6.

132. Adam CL, Findlay PA. Effect of nutrition on testicular growth and plasma concentrations of gonadotrophins, testosterone and insulin-like growth factor I (IGF-I) in pubertal male Soay sheep. J Reprod Fertil 1997;111:121-5.

133. Nolan CJ, Neuendorff DA, Godfrey RW, et al. Influence of dietary energy intake on prepubertal development of Brahman bulls. J Anim Sci 1990;68:1087-96.

134. Slob AK, Vreeburg JT, Van der Werff ten Bosch JJ. Body growth, puberty and undernutrition in the male guinea-pig. Br J Nutr 1979;41:231-7.

135. Ronnekleiv OK, Ojeda SR, McCann SM. Undernutrition, puberty and the development of estrogen positive feedback in the female rat. Biol Reprod 1978;19:414-24.

136. Dorgan JF, Hunsberger SA, McMahon RP, et al. Diet and sex hormones in girls: findings from a randomized controlled clinical trial. J Natl Cancer Inst 2003;95:132-41.

137. Dorgan JF, McMahon RP, Friedman LA, et al. Diet and sex hormones in boys: findings from the dietary intervention study in children. J Clin Endocrinol Metab 2006;91:3992-6.

138. Campbell BC, Gillett-Netting $\mathrm{R}$, Meloy M. Timing of reproductive maturation in rural versus urban Tonga boys, Zambia. Ann Hum Biol 2004;31:213-27.

139. Leonhardt M, Lesage J, Croix D, et al. Effects of perinatal maternal food restriction on pituitary-gonadal axis and plasma leptin level in rat pup at birth and weaning and on timing of puberty. Biol Reprod 2003;68:390-400.

140. Hauspie RC, Vercauteren M, Susanne C. Secular changes in growth and maturation: an update. Acta Paediatr Supp/ 1997:423:20-7.

141. Tanner JM. Growth at adolescence. Oxford: Blackwell Scientific Publications, 1955

142. Schooling CM, Jiang CO, Lam TH, et al. Life-course origins of social inequalities in metabolic risk in the population of a developing country. Am J Epidemiol 2008;167:419-28.

143. Marmot MG, Syme SL. Acculturation and coronary heart disease in Japanese-Americans. Am J Epidemiol 1976;104:225-47.

144. Yano K, Blackwelder WC, Kagan A, et al. Childhood cultural experience and the incidence of coronary heart disease in Hawaii Japanese men. Am J Epidemiol 1979:109:440-50.

145. Schooling CM, Lam TH, Thomas GN, et al. Growth environment and sex differences in lipids, body shape and diabetes risk. Plos One 2007;2:e1070.

146. Schooling CM, Lam TH, Ho SY, et al. Does economic development contribute to sex differences in ischaemic heart disease mortality? Hong Kong as a natural experiment using a case-control study. BMC Public Health 2008;8:32. 
147. Chung RY, Schooling CM, Cowling BJ, et al. How does socioeconomic development affect risk of mortality? An age-period-cohort analysis from a recently transitioned population in China. Am J Epidemiol 2010;171:345-56.

148. Hui LL, Schooling CM, Cowling BJ, et al. Are universal standards for optimal infant growth appropriate? Evidence from a Hong Kong Chinese birth cohort. Arch Dis Child 2008:93:561-5.

149. Schooling CM, Jiang C, Heys M, et al. Is leg length a biomarker of childhood conditions in older Chinese women? The Guangzhou Biobank Cohort Study. J Epidemiol Community Health 2008:62:160-7.

150. Schooling $\mathbf{C M}$, Jiang CQ, Heys $\mathbf{M}$, et al. Are height and leg length universal markers of childhood conditions? The Guangzhou Biobank Cohort Study. J Epidemiol Community Health 2008;62:607-14.

151. Webb E, Kuh D, Peasey A, et al. Childhood socioeconomic circumstances and adult height and leg length in central and eastern Europe. J Epidemiol Community Health 2008:62:351-7.
152. Tanner JM, Whitehouse $\mathrm{RH}$, Hughes PC, et al. Relative importance of growth hormone and sex steroids for the growth at puberty of trunk length, limb length, and muscle width in growth hormone-deficient children. J Pediatr 1976:89:1000-8.

153. Ong K, Beardsall K, de Zegher F. Growth hormone therapy in short children born small for gestational age. Early Hum Dev. 2005:81:973-80.

154. Schooling CM, Jiang CQ, Zhang WS, et al. Visceral adiposity would be expected to predict incident diabetes better in women than men. Diabetologia 2010;53:393-5.

155. Wong I0, Cowling BJ, Law SC, et al. Understanding socio-historical imprint on cancer risk by age-period-cohort decomposition in Hong Kong. J Epidemiol Community Health 2010;64:596-603.

156. Lassek WD, Gaulin SJC. Cost and benefits of fat-free muscle mass in men: relationship to mating success, dietary requirements, and native immunity. Evolution and Human Behaviour 2009;30:322-8. 